\title{
Genetic pathways, prevention, and treatment of sporadic colorectal cancer
}

\author{
Rasika Mundade ${ }^{1}$, Thomas F. Imperiale ${ }^{2}$, Lakshmi Prabhu ${ }^{1}$, Patrick J. Loehrer ${ }^{3}$, \\ Tao Lu $\mathbf{L}^{1,4}$ \\ ${ }^{1}$ Department of Pharmacology and Toxicology, Indiana University School of Medicine, Indianapolis, IN USA \\ ${ }^{2}$ Division of Gastroenterology and Hepatology, Regenstrief Health Center, Roudebush VA Medical Center, Indianapolis, IN \\ USA \\ ${ }^{3}$ Division of Hematology and Oncology, Indiana Cancer Pavilion, Indianapolis, IN USA \\ ${ }^{4}$ Department of Biochemistry and Molecular Biology, Indiana University School of Medicine, Indianapolis, IN USA \\ Correspondence to: Tao Lu, email: lut@iupui.edu
}

Keywords: colon cancer, genetic pathway, sporadic

Received: April 19, $2014 \quad$ Accepted: June 28, 2014

Published: June 30, 2014

This is an open-access article distributed under the terms of the Creative Commons Attribution License, which permits unrestricted use, distribution, and reproduction in any medium, provided the original author and source are credited.

\section{ABSTRACT:}

Epithelial cancer of the colon and rectum, also known as colorectal cancer (CRC), results from a progressive accumulation of genetic and epigenetic alterations that lead to uncontrolled growth of colonocytes, the cells lining the colon and rectum. CRC is the second leading cause of cancer-related deaths and the third most common cancer in men and in women in the U.S. Of all the patients diagnosed with CRC every year, it is estimated that the vast majority of CRCs are non-hereditary "sporadic cancers" with no apparent evidence of an inherited component. Sporadic CRC results from the cumulative effects of multiple genetic and epigenetic alterations caused by somatic mutations, which may themselves be the indirect result of several environmental factors. This review examines our current understanding of the major genetic alterations leading to colon cancer, options for prevention and early detection of CRC, and the currently available treatment approaches that may target these different genetic alterations.

\section{INTRODUCTION:}

$\mathrm{CRC}$ is a common, heterogeneous disease that arises through the aggregate effects of multiple genetic mutations and epigenetic alterations involving genes that regulate cell growth and differentiation. There are approximately 160,000 new cases of CRC every year in the United States and approximately one-third of CRC patients die from the disease [1]. In the United States, the lifetime risk of developing CRC for both men and women is $6 \%$ and the average age at diagnosis is 66 years [2]. Though there has been considerable advancement in the management of CRC, mortality remains high and unchanged with the 5 -year survival rate of only $62 \%$, which is attributable largely to complications of metastatic disease [2].

CRC presents with a broad spectrum of neoplasms, ranging from benign growths to invasive cancer. CRC starts in the inner lining of the colon and/or rectum as a growth of tissue called a polyp slowly growing through some or all of its layers. A particular type of polyp called the adenomatous polyp or adenoma is a benign tumor that may undergo malignant transformation to cancer. This malignant transformation is the result of mutation or deletion of major regulator genes, resulting first in hyperplasia moving toward adenoma to carcinoma and then metastasis [3].

A present estimate is that between $15-30 \%$ of CRCs may have a major hereditary component, given the occurrence of CRC in first- or second-degree relatives [4]. Most of the colorectal heritable syndromes are attributable to either familial adenomatous polyposis (FAP) or hereditary nonpolyposis colorectal cancer (HNPCC) [5]. It is important to note, however, that most cases of CRCs (70-85\%) are "sporadic" and the patients have no identifiable genetic risk factors. The development of sporadic colon cancer is thought to be influenced 
by diet, lifestyle, environmental factors, and acquired somatic mutations [6]. The spectrum of somatic mutations contributing to the pathogenesis of $\mathrm{CRC}$ is likely to be far more extensive than previously appreciated. Thus elucidating the underlying genetic pathways in the genesis of CRC would provide fertile ground for basic research and may also lead to potential prognostic information and targets for novel therapies.

\section{Genetic pathways of sporadic colon cancer:}

It is well established that sporadic CRC is a genetic disease caused by sequential accumulation of mutations in multiple genes. Over the past three decades, molecular genetic studies have identified several crucial gene defects that underlie predisposition to sporadic CRC [5]. As shown in Figure 1, there are three major genetic mechanisms responsible for sporadic CRC, namely chromosomal instability (CIN); microsatellite instability (MSI) and the $\mathrm{CpG}$ island methylator phenotype (CIMP) pathways [7]. The majority of sporadic CRCs are due to events that result from aberrations in the CIN pathway [8].

\section{CIN pathway:}

The CIN pathway is an adenoma-carcinoma sequence model (Fig. 1A) which suggests that a stepwise pattern of mutational activation of oncogenes and inactivation of tumor suppressor genes result in CRC [9]. The genomic changes include activation of proto-oncogenes KRAS, c-Src, c-Myc and inactivation of at least three tumor suppressor genes, such as the loss of Adenomatous polyposis coli (APC) gene, tumor suppressor p53 (TP53) gene, and heterozygosity for the

\section{A. Chromosomal Instability (CIN) Pathway}

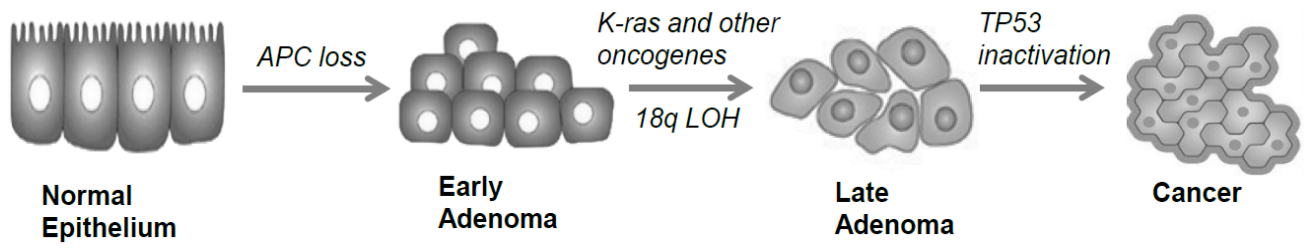

\section{B. Microsatellite Instability (MSI) Pathway}
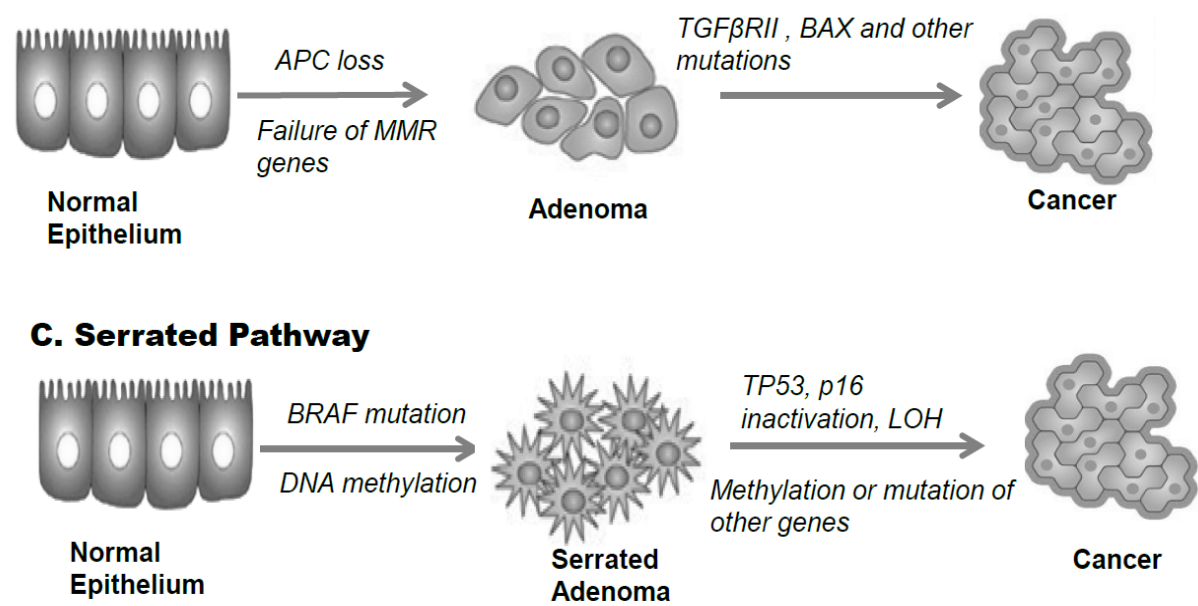

Figure 1:Multiple genetic pathways in colorectal cancer pathogenesis. Three distinct parallel pathways are implicated in CRC pathogenesis: Chromosomal Instability (CIN), Microsomal Instability (MSI), and Serrated Pathway. The sequential genetic and epigenetic changes occurring in each pathway are simplified. (A) The CIN pathway is driven by inactivating mutations in tumor suppressor genes, such as the adenomatous polyposis coli (APC) gene and activating mutations in proto-oncogenes, such as KRAS etc. which lead to increased clonal expansion of the cells. Subsequent loss of heterozygosity (LOH) for the long arm of chromosome 18 (18q) and loss of tumor suppressor TP53 confer these expanding cells with additional growth advantages which ultimately leads to invasive cancers. (B) The MSI pathway is driven by the loss of APC gene, and is characterized by inactivation of the mismatch repair (MMR) genes, such as MutL homolog 1 (MLH1) etc. The inactivation of MMR genes mostly is caused by epigenetic silencing via promoter hypermethylation. The failure of MMR genes subsequently leads to mutations in specific target genes involved in proliferation and cellular differentiation such as transforming growth factor $\beta$ receptor II (TGF $\beta$ RII); proteins involved in apoptosis regulation such as BAX and others, ultimately leading to microsatellite unstable invasive tumors. (C) The Serrated Pathway is driven by hypermethylation of genes and is characterized by presence of proto-oncogene BRAF mutation which causes increased MAPKs/ERKs signaling, leading to increased cell proliferation. Subsequent methylation of other genes and loss of tumor suppressor genes such as TP53, p16 etc. will lead to CRC. 
Table 1: Average-Risk Screening Tests and Intervals

\begin{tabular}{|c|c|c|c|}
\hline & & Guideline Organization & \\
\hline Test & $\begin{array}{c}\text { American Cancer Society- } \\
\text { Multi-society Task Force- } \\
\text { American College of Radiology } \\
{[32]}\end{array}$ & $\begin{array}{c}\text { United States Preventive } \\
\text { Services Task Force } \\
{[33]} \\
\end{array}$ & $\begin{array}{c}\text { American College of } \\
\text { Gastroenterology } \\
{[34]}\end{array}$ \\
\hline $\begin{array}{l}\text { Guaiac-based fecal occult blood } \\
\text { test (gFOBT) }\end{array}$ & Not recommended & Annually & Not recommended \\
\hline $\begin{array}{l}\text { High sensitivity gFOBT or fecal } \\
\text { immunochemical test (FIT) }\end{array}$ & Annually & Annually & Annually \\
\hline Sigmoidoscopy & Every 5 years & $\begin{array}{l}\text { Every } 5 \text { years } \\
\text { (suboptimal) }\end{array}$ & Every 5 years \\
\hline $\begin{array}{l}\text { High sensitivity gFOBT or FIT } \\
\text { and sigmoidoscopy }\end{array}$ & Every 1 and 5 years, respectively & $\begin{array}{c}\text { Mid-interval and every } 5 \text { years, } \\
\text { respectively }\end{array}$ & $\begin{array}{c}\text { Every } 1 \text { and } 5-10 \text { years, } \\
\text { respectively }\end{array}$ \\
\hline Double contrast barium enema & Every 5 years & Not recommended & Not recommended \\
\hline Fecal DNA & Yes, interval not given & Not recommended & Every 3 years \\
\hline $\begin{array}{l}\text { Computed tomographic } \\
\text { colonography }\end{array}$ & Every 5 years & Not recommended & Every 5 years \\
\hline Colonoscopy & Every 10 years & Every 10 years & Every 10 years \\
\hline
\end{tabular}

long arm of chromosome 18 (18q LOH) [10, 11].

Among the earliest events in sporadic CRC progression pathway is the loss of the APC gene. Genetic disruption of the APC gene or its inactivation by hypermethylation of the APC promoter leads to Wnt/ $\beta$ catenin signaling activation. This process is hypothesized to be the key event for adenoma initiation $[12,13]$. Mutant APC protein increases stabilization of $\beta$-catenin and leads to its accumulation in the cytoplasm and its eventual translocation into the nucleus to act as a coactivator of the T-cell factor/lymphoid enhancer factor family (TCF/LEF) transcription factors. This process in turn will activate a repertoire of genes that are involved in cell proliferation and growth [14]. The importance of $\mathrm{Wnt} / \beta$-catenin signaling in the genesis of $\mathrm{CRC}$ is further reflected in many CRCs (50\%) with intact APC genes but high frequency of activating mutations in $\beta$-catenin that harbors functionally significant phosphorylation sites [15].

Another important genetic pathway contributing to CIN is KRAS. The KRAS gene belongs to the RAS family of oncogenes and is mutated in $30-50 \%$ of CRCs [16]. RAS proteins play important roles in cell division, cell differentiation, and apoptosis. Multiple cellular functions are regulated by activated RAS through different pathways. One of the best characterized pathways regulated by RAS family is the Raf-mitogen-activated protein kinase kinase (MEK)-extracellular signalregulated kinase (ERK) pathway, which is involved in the control of cell cycle progression [17]. Mutation in
KRAS disrupts the RAS signaling pathway leading to tumorigenesis. These mutations impair the intrinsic Guanosine-5'-triphosphate (GTP)ase activity of KRAS, allowing KRAS to accumulate in the active, GTP-bound conformation and lead to constitutive activation of its downstream pro-proliferative signaling pathways [18].

Studies have also demonstrated the loss of tumor suppressor TP53 gene and 18q LOH as major contributors to the CIN phenotype [19]. The TP53 gene is significantly involved in the control of the cell cycle and apoptosis and is commonly mutated in CRC, leading to uninhibited cell growth [9]. SMAD4, an important tumor suppressor present in chromosome 18q21.1 is lost by $18 \mathrm{q}$ deletion, resulting in tumorigenesis via the transforming growth factor $\beta$ (TGF $\beta$ ) pathway [20]. The presence of $18 \mathrm{q} \mathrm{LOH}$ has been proposed as a worse prognostic marker for patient survival in CRC [21]. Recently, mutations in genes of phosphatidylinositol 4,5-bisphosphate 3-kinase catalytic subunit $\alpha$ (PIK3CA) and TGF $\beta$ receptor (TGFBR) also have been shown to play a role in CRC development [22].

\section{MSI pathway:}

In addition to CIN pathway, about $10-15 \%$ of sporadic CRC are due to the MSI pathway (Fig. 1 B). MSI is the condition of genetic hypermutability that results from impaired DNA mismatch repair (MMR). In other words, MSI is the phenotypic evidence that MMR isn't functioning normally. The proteins involved in MMR form 
a complex that binds to the mismatch, identifies the correct strand of DNA, then subsequently excises the error and repairs the mismatch. Cells with abnormally functioning MMR tend to accumulate mutations (insertions or deletions) in microsatellites located in DNA coding regions, generating frameshift mutations and subsequently leading to sporadic CRCs [23].

Inactivation of MMR genes occur either through aberrant methylation of promoter $\mathrm{CpG}$ of the MutL homolog 1 (MLH1) gene or point mutations in one of the MMR genes, with the former reason accounting for most of the cases of MMR inactivation [22]. As a result of defects in the DNA MMR system, MSI cancers more readily acquire mutations in important cancer-associated genes as compared to cells that have an effective DNA MMR system. Among the earliest events in the MSIdependent CRC progression, similar to the CIN pathway (Fig. 1A), loss of function of the APC gene product (Fig. 1B) also appears to play an important role in predisposing persons with germ line APC mutations to sporadic CRCs [22].

Clinically, solely based on the extent of MSI, CRCs can be classified as MSI-high, MSI-low, or microsatellite stable (MSS) [23]. As compared with MSS/MSI-low tumors, MSI-high tumors form a well-defined group with distinct clinicopathological features. This type of $\mathrm{CRC}$ often arises from the epigenetic silencing of the MMR gene, such as MLH1 (Fig. 1B), so it belongs to the traditional MSI pathway. In contrast, MSS/MSI-low tumors arise through CIN pathway (Fig.1A). Overall, MSI-high tumors have a better long-term prognosis than MSI-low/MSS tumors. In general, MSI and CIN $\mathrm{CRC}$ respond differently to chemotherapeutics and have implications for specialized management of patients [24, $25]$.

\section{Serrated pathway:}

The name of this pathway is attributable to the morphologically serrated appearance of the precursor lesions. Different from the CIN (Fig.1A) and MSI (Fig.1B) pathways, in which the sporadic CRCs are mainly initiated through classical APC mutations, the Serrated pathway initiated CRCs are highlighted by the presence of BRAF (protein kinase B-Raf) mutation and epigenetic silencing of genes that are involved in cell differentiation, DNA repair, and cell-cycle control, but not APC (Fig. 1C) [26, 27].

BRAF, a member of the RAF kinase family is a serine/threonine-specific protein kinase that plays a key role in regulating the MAPKs/ERKs (mitogenactivated protein kinases/extracellular signal-regulated kinases) signaling pathway, which affects cell division, differentiation, and secretion. Point mutation in BRAF (V600E) causes constitutive activation of this kinase as well as its insensitivity to negative feedback mechanisms, leading to enhanced MAPK/ERK signaling [28]. This overactive signaling cascade reaches cellular DNA within the nucleus and triggers downstream effectors to induce uncontrolled cell proliferation, evasion of immune response, angiogenesis [through MAPK-dependent activation of hypoxia-inducible factor $1 \alpha$ (HIF-1 $\alpha$ ), vascular endothelial growth factor (VEGF)], tissue invasion, and metastasis (via upregulation of several proteins involved in migration, integrin signaling, and cell contractility), as well as resistance to apoptosis [29].

Among the epigenetically silenced genes in Serrated pathway, p16 (also known as cyclin-dependent kinase inhibitor 2A, multiple tumor suppressor 1) is one of the most well- characterized tumor suppressor genes. The p16 tumor suppressor protein functions as an inhibitor of CDK4 and 6 (cyclin-dependent kinase 4 and 6), the D-type cyclin-dependent kinases that initiate the phosphorylation of the retinoblastoma $(\mathrm{Rb})$ tumor suppressor protein. The progression of sporadic CRCs through the Serrated pathway is accelerated by p16 inactivation through promoter hypermethylation.

It is possible that no two CRCs are alike and only a few mutations are common to most sporadic CRCs. Therefore, each tumor has its own unique combination of genetic alterations. In addition to the pathways described, the heterogeneity of CRCs is further attributed to the interactions of the described pathways (Fig.1) with other less described or still undescribed pathways. An example can be seen in the Landscaper Defect pathway, in which the defective cells are derived from the stroma and epithelial tumorigenesis is the result of an abnormal microenvironment [30]. These different pathways will undoubtedly interact with each other, and may even modify these routes to carcinogenesis.

\section{Prevention:}

Although the incidence and mortality rates from CRC are declining steadily in the United States, health disparities in cancer screening, treatment, and survival still persist [31]. Because CRC and most adenomatous polyps are usually asymptomatic during the early stages, screening is critical to reducing morbidity and mortality. Over the past two decades, screening has contributed to a significant decline in both the number of CRC cases and the number of CRC deaths. While several strategies are recommended by the three major guideline organizations [32-34] (Table 1), the mainstay of screening involves fecal occult blood testing with either high-sensitivity guaiac-based fecal occult blood tests (FOBT) or fecal immunochemical tests (FIT), and bowel examination by lower endoscopy. Colonoscopy is the most widely used screening test used in the U.S. [35]. While it has the highest diagnostic sensitivity and specificity of all available tests, it is uncertain whether a strategy of colonoscopy every ten years is best. It is possible that 
a less sensitive test that is frequently applied may be as effective as colonoscopy, as suggested by simulation models [36-40]. Such uncertainty and resulting equipoise constitute the basis for two ongoing randomized trials of colonoscopy versus FIT being conducted in Spain [41] and by the Veterans Affairs in the U.S. [42], the results of which will be available in ten years or so. Recently, stool DNA testing has been shown to be more sensitive than FIT for both CRC and advanced, precancerous polyps [43] and may be an effective non-invasive alternative to annual FIT. CRC screening recommendations by all three guideline organizations are expected to be updated within 1-2 years.

\section{Treatment:}

Depending on the stage and progression state of the disease, treatment regimens for CRCs include: colectomy (Stage 0, Stage I and early Stage II colon cancers), postoperative adjuvant chemotherapy (Stage III and some Stage II colon cancers), chemotherapy with multi-drug therapy including 5-fluorouracil and leucovorin and CapeOx (capecitabine and oxaliplatin) (Stage II) and radiation therapy (recurrent or advanced disease). Another chemotherapeutic agent, imnotecan (CPT11) has been shown to improve efficacy in CRCs [44]. Recently, oxaliplatin has been shown to induce immune thrombocytopenia in a CRC patient [45].

Genetically engineered monoclonal antibodies are used in treating CRCs. Cetuximab and panitumumab are anti-EGFR monoclonal antibodies that block the EGFR signaling pathway. These two drugs are used in the treatment of metastatic CRC in combination with conventional chemotherapy or as single agent. Clinical studies have shown that combination therapy with irinotecan plus cetuximab increases the survival rates and response in metastatic CRC patients as compared to irinotecan alone [22]. Recently, the U.S. Food and Drug Administration (FDA) approved bevacizumab for treatment of CRC. Bevacizumab is a recombinant humanized monoclonal antibody that binds to human VEGF, thereby preventing the interaction of VEGF with its receptors. Stivarga (regorafenib), a multi-kinase inhibitor, is another drug that has been approved by FDA for the treatment of metastatic CRC that has continued to spread after treatment. Evaluation of recombinant vaccines for colon cancer has begun with concurrent technologies in the fields of molecular biology and immunology. Very recently, Ye et al [46] showed that recombinant salmonella-based 4-1BBL vaccine enhances $\mathrm{T}$ cell immunity and inhibits the development of CRC in rats. Research in the field to target alternative pathways such as the anti-apoptotic signaling pathways including $\mathrm{NF}-\kappa \mathrm{B}, \mathrm{Bcl}-2$, and the TRAIL receptor to treat $\mathrm{CRC}$ is still ongoing [47].

The Genetic Sequencing technique has revolutionized monitoring of disease progression, relapse, and residual disease in CRCs [22]. Bass et al [48] reported whole genome sequencing from CRC patients. This study led to deeper understanding of the essential gene fusions and other oncogenic events in CRC. Leary et al [49] provided a massive parallel sequencing using the PARE (personalized analysis of rearranged ends) approach for the development of personalized biomarkers to enhance the clinical management of CRC patients.

The pace of recent advances in our understanding of the molecular basis of CRC and expansion in the drugs designed to treat $\mathrm{CRC}$ have led to substantial gains in quality of life in CRC patients. However, the significant burden of CRC on public health still remains. Like most other cancer therapeutics, these treatment regimens are associated with side effects and have not yet shown significant efficacy in most instances. Another key factor that limits progress in CRC chemoprevention is the pace of clinical research. There is a significant lack of awareness among people to undergo CRC screening despite established and available techniques. Overcoming these challenges will bring cause for optimism and room for hope in treating CRCs.

\section{ACKNOWLEDGEMENTS:}

We thank Ms. Lisa King at the Department of Pharmacology and Toxicology at Indiana University School of Medicine for her generous and professional help with revising this review. The research is supported by grants 23-862-07TL (to TL) and 036433730102 (to TL).

\section{Abbreviations:}

APC, adenomatous polyposis coli gene; Bcl-2, B-cell lymphoma 2; BRAF, protein kinase B-Raf; CDK4 cyclin-dependent kinase 4; CDK6, cyclin-dependent kinase 6; c-Myc v-myc, avian myelocytomatosis viral oncogene homolog; CIMP, $\mathrm{CpG}$ island methylator phenotype, CIN chromosomal instability; CRC, colorectal cancer; c-Src, proto-oncogene tyrosine-protein kinase Src; DNA, deoxyribonucleic acid; 18q LOH, loss of long arm of chromosome 18; EGFR, epidermal growth factor receptor; ERK, extracellular signal-regulated kinases; FAP, familial adenomatous polyposis; FDA, Food and Drug Administration; FIT, fecal immunochemical test; FOBT, fecal occult blood test; GTP, guanosine-5'triphosphate; HIF-1 $\alpha$, hypoxia-inducible factor $1 \alpha$; HNPCC, hereditary nonpolyposis colorectal cancer; KRAS, Kirsten Rat Sarcoma Viral Oncogene Homolog; LEF, lymphoid enhancer factor; MAPK, mitogenactivated protein kinase; MEK, mitogen-activated protein kinase kinase; MLH1, mutL homolog 1; MMR, mismatch repair; MSI, microsatellite instability; MSS, microsatellite stable; NF- $\kappa \mathrm{B}$ nuclear factor $\kappa \mathrm{B}$; PARE, personalized analysis of rearranged ends; PIK3CA, 
phosphatidylinositol 4,5-bisphosphate 3-kinase catalytic subunit $\alpha ; \mathrm{Rb}$, retinoblastoma; Raf, rapidly accelerated fibrosarcoma; Ras, rat sarcoma; SMAD4, mothers against decapentaplegic homolog 4; TCF, T-cell factor; TGF $\beta$, transforming growth factor $\beta$; TGF $\beta$, transforming growth factor $\beta$ receptor; TP53, tumor suppressor $\mathrm{p} 53$ gene; TRAIL, TNF-related apoptosis-inducing ligand; VEGF, vascular endothelial growth factor; Wnt, wingless

\section{REFERENCES:}

1. Jemal A, Siegel R, Ward E, Hao Y, Xu J, Thun MJ. Cancer statistics. Cancer J. Clin 2009; 58: 225-49.

2. Hawk ET, Levin B. Colorectal cancer prevention. J Clin Oncol. 2005; 23: 378-91.

3. Fleshman JW, Chung TP. The genetics of sporadic colon cancer. Seminars in Colon and Rectal Surgery. 2004; 13: 128-35.

4. Taylor DP, Burt RW, Williams MS, Haug PJ, CannonAlbright LA. Population-based family history-specific risks for colorectal cancer: a constellation approach. Gastroenterology. 2010; 138: 877-85.

5. Fearon ER. Molecular genetics of colorectal cancer. Annu Rev Pathol. 2011; 6: 479-507.

6. Slattery JL. Diet, lifestyle, and colon cancer. Semin Gastrointest Dis. 2000; 11: 1142-46.

7. Pino MS, Chung DC. The chromosomal instability pathway in colon cancer. Gastroenterology. 2010; 138: 2059-72.

8. Lengauer C, Kinzler KW, Vogelstein B. Genetic instabilities in human cancers. Nature.1998; 396: 643-49.

9. Vogelstein B, Fearon ER, Hamilton SR, Kern SE, Preisinger AC, Leppert M, Nakamura Y, White R, Smits AM, Bos JL. Genetic alterations during colorectal-tumor development. N Engl J Med. 1988; 319: 525-32.

10. Vogelstein B, Kinzler KW. The multistep nature of cancer. Trends Genet. 1993; 9: 138-41.

11. Kinzler KW, Vogelstein B. Colorectal tumors. Genetic Basis of Human Cancer. 2002; 2: 583-612.

12. Powell S, Zilz N, Beazer-Barclay Y et al. APC mutations occur early during colorectal tumorigenesis. Nature. 1992; 359: 235-37.

13. Esteller M, Sparks A, Toyota M et al. Analysis of adenomatous polyposis coli promoter hypermethylation in human cancer. Cancer Res. 2000; 60: 4366-71.

14. Mann B, Gelos M, Siedow A et al. Target genes of betacatenin-T-cell-factor/lymphoid-enhancer-factor signaling in human colorectal carcinomas. Proc Natl Acad Sci U S A. 1999; 96: 1603-08.

15. Sparks A, Morin P, Vogelstein B et al. Mutational analysis of the APC/beta-catenin/Tcf pathway in colorectal cancer. Cancer Res. 1998; 58: 1130-34.

16. Tan $\mathrm{C}, \mathrm{Du} \mathrm{X}$. KRAS mutation testing in metastatic colorectal cancer. World J Gastroenterol. 2012; 18:
5171:80.

17. Pruitt K, Der C. Ras and Rho regulation of the cell cycle and oncogenesis. Cancer Lett. 2001; 171: 1-10.

18. Schubbert S1, Shannon K, Bollag G. Hyperactive Ras in developmental disorders and cancer. Nat Rev Cancer. 2007; 4: 295-308.

19. Fearon E, Vogelstein B. A genetic model for colorectal tumorigenesis. Cell. 1990; 61: 759-67.

20. Alberts J, Lewis R, Roberts W. Molecular Biology of the Cell. 5th ed. Garland Science, Taylor and Francis Group; New York, NY, USA: 2008. The molecular basis of cancer cell behaviour; pp. 1251-52.

21. Ogino S, Kawasaki T, Kirkner G, Ohnishi M, Fuchs C. 18q loss of heterozygosity in microsatellite stable colorectal cancer is correlated with $\mathrm{CpG}$ island methylator phenotypenegative (CIMP-0) and inversely with CIMP-low and CIMP-high. BMC Cancer. 2007; 7:72-96.

22. Armaghany T, Wilson JD, Chu Q, Mills G. Genetic Alterations in Colorectal Cancer. Gastrointest Cancer Res. 2012; 5: 19-27.

23. Geiersbach KB, Samowitz WS. Microsatellite instability and colorectal cancer. Arch Pathol Lab Med. 2011; 135: 1269-77.

24. Fang DC, Jass JR, Wang DX, Zhou XD, Luo YH, Young $\mathrm{J}$. Infrequent loss of heterozygosity of APC/MCC and DCC genes in gastric cancer showing DNA microsatellite instability. J Clin Pathol. 1999; 52: 504-08.

25. Boland CR, Goel A. Microsatellite instability in colorectal cancer. Gastroenterology. 2010; 138: 2073-87.

26. Jass JR, Young J, Leggett BA. Evolution of colorectal cancer: change of pace and direction. J Gastroenterol Hepatol. 2002; 17-26.

27. Leggett $\mathrm{B}$, Whitehall V. Role of the serrated pathway in colorectal cancer pathogenesis. Gastroenterology. 2010; 138: 2088-100.

28. Rustgi AK. BRAF: A Driver of the Serrated Pathway in Colon Cancer. Cancer Cell. 2013; 24: 1-2.

29. Ascierto PA1, Kirkwood JM, Grob JJ, Simeone E, Grimaldi AM, Maio M, Palmieri G, Testori A, Marincola FM, Mozzillo N. The role of BRAF V600 mutation in melanoma. J Transl Med. 2012; 10: 85-111.

30. Kinzler KW, Vogelstein B. Landscaping the cancer terrain. Science. 1998; 280: 1036-37.

31. Gellad ZF, Provenzale D. Colorectal cancer: national and international perspective on the burden of disease and public health impact. Gastroenterology. 2010; 138: 2177 90.

32. Levin B, Lieberman DA, McFarland B, Andrews KS, Brooks D, Bond J, et al. Screening and surveillance for the early detection of colorectal cancer and adenomatous polyps, 2008: a joint guideline from the American Cancer Society, the US Multi-Society Task Force on Colorectal Cancer, and the American College of Radiology. Gastroenterology. 2008; 134: 1570-95. 
33. Screening for colorectal cancer: U.S. Preventive Services Task Force recommendation statement. Ann Intern Med. 2008; 149: 627-37.

34. Rex DK, Johnson DA, Anderson JC, Schoenfeld PS, Burke CA, Inadomi JM. American College of Gastroenterology guidelines for colorectal cancer screening 2009 [corrected]. Am J Gastroenterol. 2009; 104: 739-50.

35. Cancer screening - United States, 2010. MMWR Morb Mortal Wkly Rep. 2012; 61: 41-5.

36. Sharaf RN, Ladabaum U. Comparative effectiveness and cost-effectiveness of screening colonoscopy vs. sigmoidoscopy and alternative strategies. Am J Gastroenterol. 2013; 108: 120-32.

37. Lansdorp-Vogelaar I, Knudsen AB, Brenner H. Costeffectiveness of colorectal cancer screening. Epidemiol Rev. 2011; 33: 88-100.

38. Parekh M, Fendrick AM, Ladabaum U. As tests evolve and costs of cancer care rise: reappraising stool-based screening for colorectal neoplasia. Aliment Pharmacol Ther. 2008; 27: 697-712.

39. Heitman SJ, Hilsden RJ, Au F, Dowden S, Manns BJ. Colorectal cancer screening for average-risk North Americans: an economic evaluation. PLoS Med. 2010; 9: 7:e1000370.

40. Pignone MP, Russell L, Wagner JL, Editors. Economic Models of Colorectal Cancer Screening in AverageRisk Adults: Workshop Summary. In: Press TNA, ed. Washington, D.C.: Institute of Medicine and National Research Council. 2005.

41. Colonoscopy versus fecal immunochekical testing in colorectal cancer screening. Quintero E, Castells A, Bujanda L, Cubiella J, Salas D, Lanas Á, Andreu M, Carballo F, Morillas JD, Hernández C, Jover R, Montalvo I, Arenas J, Laredo E, Hernández V, Iglesias F, Cid E, Zubizarreta R, Sala T, Ponce M, Andrés M, Teruel G, Peris A, Roncales MP, Polo-Tomás M, Bessa X, Ferrer-Armengou O, Grau J, Serradesanferm A, Ono A, Cruzado J, Pérez-Riquelme F, Alonso-Abreu I, de la Vega-Prieto M, Reyes-Melian JM, Cacho G, Díaz-Tasende J, Herreros-de-Tejada A, Poves C, Santander C, González-Navarro A; COLONPREV Study Investigators. N Engl J Med. 2012; 366: 697-706.

42. URL: http://www.vaoutcomes.org/our_work/confirm/

43. Imperiale $\mathrm{TF}$, Ransohoff DF, Itzkowitz $\mathrm{SH}$, Levin TR, Lavin P, Lidgard GP, Ahlquist DA, Berger BM. Multitarget Stool DNA Testing for Colorectal-Cancer Screening. N Engl J Med. 2014; 370: 1287-97.

44. Magrini R, Bhonde MR, Hanski ML, Notter M, Scherübl H, Boland CR, Zeitz M, Hanski C. Cellular effects of CPT-11 on colon carcinoma cells: dependence on p53 and hMLH1 status. Int J Cancer. 2002; 101: 23-31.

45. Akdeniz A, Kucukoztas N, Yalcin S, Akcali Z, Altundag O. Oxaliplatin-induced immune thrombocytopenia in a patient with colon cancer. Am Surg. 2011; 77:E9.

46. Ye J, Li L, Zhang Y, Zhang X, Ren D, Chen W.
Recombinant salmonella-based 4-1BBL vaccine enhances $\mathrm{T}$ cell immunity and inhibits the development of colorectal cancer in rats: in vivo effects of vaccine containing 4-1BBL. Journal of Biomedical Science. 2013; 20: 8-25.

47. Oikonomou E, Pintzas A. Cancer genetics of sporadic colorectal cancer: BRAF and PI3KCA mutations, their impact on signaling and novel targeted therapies. Anticancer Res. 2006; 26: 1077-84.

48. Bass AJ, Lawrence MS, Brace LE, et al. Genomic sequencing of colorectal adenocarcinomas identifies a recurrent VTI1A-TCF7L2 fusion. Nature Genet. 2011; 43: 964-68.

49. Leary RJ, Kinde I, Diehl F, et al. Development of personalized tumor biomarkers using massively parallel sequencing. Sci Transl Med. 2010; 2: 1-15. 